Running Head: CONSEQUENCES OF FALSE MEMORY

The Nature and Consequences of False Memories for Visual Stimuli

\author{
Jianqin Wang ${ }^{1}$, Henry Otgaar ${ }^{1,2}$, Mark L. Howe ${ }^{1,2}$, Felix Lippe ${ }^{1}$, Tom Smeets ${ }^{1}$ \\ ${ }^{1}$ Maastricht University, The Netherlands \\ ${ }^{2}$ City, University of London, UK
}

In Press, Journal of Memory and Language

Correspondence to Jianqin Wang, Clinical Psychological Science, Faculty of Psychology and Neuroscience, Maastricht University, PO Box 624, 6200 MD, Maastricht, the Netherlands, Tel.: +31-43-3884536, Fax: +3143-3884196. E-mail address: jane.wang@ maastrichtuniversity.nl This paper has been supported by a fellowship from China Scholarship Council (CSC) to Jianqin Wang [No. 201406100057]. 


\begin{abstract}
Different theoretical views exist regarding whether false memories contain perceptual information or are merely conceptual in nature. To address this question, we conducted three experiments to examine whether false memories for pictures had a priming effect on a perceptual closure task. In Experiment 1, participants were presented with pictorial versions of Deese/Roediger-McDermott (DRM) lists and received a recognition task. Finally, in the perceptual closure task (PCT), participants were shown degraded pictures (studied pictures, critical pictures, unrelated pictures) that became clearer over time and had to identify the object depicted as quickly as possible. The results showed that false memories for pictures did not exhibit a priming effect in the PCT. Specifically, picture identifications based on false memories for visual stimuli were significantly slower than those based on true memories and the former did not differ from that of unrelated items. In Experiments 2 and 3, we manipulated the modality (verbal vs. pictorial) of the study phase and the PCT phase. In both experiments, false memories for pictures primed pictures significantly slower than true memories in the pictorial PCT, but false memories for pictures primed words faster than true memories in the verbal PCT. Our results suggest that false memories for pictures are unlikely to contain perceptual information but rather that they are conceptual in nature.
\end{abstract}

Keywords: false memory, memory representation, perceptual closure task, DRM paradigm 


\section{The Nature and Consequences of False Memories for Visual Stimuli}

It is not uncommon that you falsely remember when you had your meeting or where you dated your girlfriend a year ago. What matters is whether these memory distortions will result in any unwanted consequences. False memories are commonly associated with negative consequences such as false accusations of child sexual abuse (Otgaar, Sauerland, \& Petrila, 2013). However, in recent years, studies have accumulated showing that false memories have adaptive value and can be beneficial under certain circumstances (Howe, 2011; Schacter, 2012). As many of these beneficial effects of false memories have been observed with verbal stimuli, the general aim of the current study is to investigate whether these same positive outcomes generalize to visual stimuli.

For example, a series of studies have demonstrated that false memories facilitate problemsolving behavior equivalent to or better than true memories (Howe, Garner, Dewhurst, \& Ball, 2010; Howe, Garner, \& Patel, 2013; Howe, Wilkinson, Garner, \& Ball, 2016; Wang, Otgaar, Howe, Smeets, Merkelbach, \& Nahouli, 2016). In these studies, participants are usually presented with associated lists (e.g., women, husband, uncle, lady, male) using the well-known Deese/Roediger-McDermott paradigm (DRM; Deese, 1959; Roediger \& McDermott, 1995). After the presentation of such DRM lists, participants commonly falsely recollect the nonpresented 'critical lure' word (i.e., man) which is associatively related to each of the list words. Then, participants are asked to solve compound remote associate task problems. Each problem is a three-word puzzle (e.g., old/hole/super) and they have to come up with a theme word (in this case, man) that could link all the three words. Importantly, when the solutions are the non- 
presented critical lures, participants solve these problems in a more efficient way than when the solutions are the words presented on the lists. Not only when using compound remote associate problems do false memories exert positive consequences, but also with analogical reasoning problems in both children (Howe, Threadgold, Norbury, Garner, \& Ball, 2013) and adults (Howe, Garner, Threadgold, \& Ball, 2015).

Additional studies have concentrated on the positive priming effects of false memories on an adapted perceptual closure task (PCT) - a measure loosely linked to intelligence (Otgaar, Howe, Beers, van Hoof, Bronzwaer, \& Smeets, 2015). In this PCT, participants are presented with degraded stimuli that become clearer over time and they have to indicate what the stimuli are (e.g., a certain word) as soon as they recognize the stimuli. The PCT requires people to fill in the missing parts of a degraded image, which is similar to subtasks in certain intelligence tasks (Luteijn \& Barelds, 2004). In Otgaar et al.’s (2015) study, participants received DRM lists and a recognition test and they were then exposed to the PCT (Experiment 1). Here, they were presented with degraded versions of both presented words and the critical lures. The significant finding was that false memories for the critical lures primed the PCT faster than the presented words. The same finding emerged when no recognition task was included (Experiment 2). Again, this is evidence indicating the processing advantages associated with false over true memories.

The above lines of research clearly demonstrate the positive value of false memories. However, these findings may be somewhat limited inasmuch as the stimuli used in these studies were purely conceptual (i.e., words) and no studies have examined whether false memories for pictures have any positive consequence on cognitive tasks such as the PCT. This question is important for the following reasons. First, research dealing with visual false memories is limited (see Miller \& Gazzaniga, 1998), but studies that have been conducted reveal that false memory rates for pictures differ from false memories for words. For example, Israel and Schacter (1997) 
found that false memories for pictures resulted in significantly lower acceptance rates than verbal false memories (see also Howe, 2006). When false memories are derived from visual scenes, recognition rates for critical lures were relative low as well $(\sim 30 \%$; Otgaar, Howe, Peters, Smeets, \& Moritz, 2014). One possible explanation for these differences in false memory rates is distinctiveness. That is, pictures contain more details which are distinct from each another and this tends to weaken the associatively-based generation of false memories (Koutstaal, Schacter, \& Brenner, 2001; Seamon, Luo, Schlegel, Greene, \& Goldenberg, 2000). So, the cognitive processes underlying visual and verbal false memories might be different, and hence, it is unknown whether false memories for visual stimuli also exert positive influences on subsequent priming tasks.

Second, spreading activation theories (Howe, Wimmer, Gagnon, \& Plumpton, 2009; Roediger, Balota, \& Watson, 2001) have been put forward to explain the positive consequences of associatively generated (e.g., verbal) false memories. In these activation theories, DRM list members (nodes) are embedded within an associative network. Activation of one conceptual node spreads to other related nodes. Activation of related but non-presented concepts not only leads to false recall/recognition of non-presented words but also triggers additional spreading activation that impacts performance on related (e.g., associative) tasks (Howe et al., 2010; Otgaar et al., 2015). When visual stimuli are presented and visual false memories are induced, it is unclear whether visual representations are integrated in this network and thus, it is unclear whether they will result in any positive priming consequences.

In theories about how information is represented in memory (e.g., Dual Coding Theory), it is thought that pictures are encoded in parallel into both imaginal and verbal representations (Paivio, 1991; Sadoski \& Paivio, 2004). If false memories derived from visual stimuli also contain perceptual representations, false memories for pictures should facilitate priming on 
imagery/perceptual tasks. Studying the consequences of visual false memories on a priming task might help uncover the mechanism underlying false memories.

\section{Perceptual vs. Conceptual False Memories}

Indeed, there is no consensus regarding whether false memories encompass a perceptual mental representation in the same way that true memories do. One line of research favors the view that the memory representation for DRM critical lures contains perceptual details. For instance, McDermott (1997) had participants study DRM lists and then perform a word-stem completion task (e.g., bas__ for the target basket) or a fragment completion task (e.g., b_s for the target basket). These tasks were referred to as perceptual priming tasks by the author. The results showed that critical lures had a significant priming effect on the stem/fragment completion rates as compared to non-studied items, although the level of priming was not as strong as studied items. McKone and Murphy (2000) replicated McDermott's (1997) results and even found that the magnitude of critical lures' priming effect was equivalent to that of studied items. The priming effects of critical lures were also found in other studies involving similar tasks such as a lexical decision task (i.e., to classify stimuli as words or nonwords) (Tajika, Neumann, Hamajima, \& Iwahara, 2005; Tse \& Neely, 2005, 2007).

The opponent view is that false memories for critical lures do not contain perceptual information. For example, Hicks and Starns (2005) manipulated the study modality of DRM lists (visual vs. auditory presentation) to examine whether critical lure priming was modality specific. The logic was that, if critical lures are perceptually encoded, visual DRM lists should induce visually encoded critical lures and auditory lists should lead to auditory encodings of critical lures. Thus, critical lure priming of the visual stem completion task should only exist in the visual study modality but not in the auditory study modality. Hicks and Starns (2005) found that critical lures had a higher word-stem completion rate than non-studied items in both the visual and 
auditory study modalities, which suggested activations of critical lures are not perceptual but perhaps conceptual in nature. In addition to failures to find modality-specific priming effects for critical lures (but see McKone \& Murphy, 2000, for a report of modality specificity), there are studies where critical lure priming was not found (or was restricted) in the lexical decision task (McKone, 2004; Meade, Watson, Balota, \& Roediger, 2007) and in the stem completion task when participants did not attempt to retrieve words from the study phase (McBride, Coane, \& Raulerson, 2006).

Importantly, different theoretical hypotheses about the mechanisms of false memory activation underlie these contrasting views. The Implicit Associative Response hypothesis (IAR; e.g., Underwood, 1965; McDermott, 1997) proposes that the presence of a word (e.g., table) may activate the encoding of a related/critical word (e.g., chair). The IAR does not predict perceptual priming of critical lures directly. McKone and Murphy (2000) extended it to the IAR/imagery hypothesis (see also Hicks \& Starns, 2005) in that the critical item might be encoded in the specific modality during the study phase (e.g., visual lists create visual (perceptual) representations of critical lures). Thus, critical lures are related to perceptual characteristics from a specific modality, which can explain why critical lures were effective in perceptual priming tasks. Alternatively, theories of false memory activation predict conceptual critical lure priming effects. The activation-monitoring (Roediger et al., 2001) and the associative-activation (Howe et al., 2009) theories suggest that processing of one concept activates a corresponding conceptual node and this activation spreads to surrounding associative concept nodes. When the DRM list items are presented, their shared associative concept - the critical lure - is most likely to be activated during encoding. Thus, these activation theories predict conceptual priming for critical lures as critical lures in the DRM paradigm primarily result from conceptual activation. However, it is also possible that perceptual features are stored along with the "nodes" in the associative 
network or they are integrated in the network in some way (Howe et al., 2009). For instance, false memories can be induced by phonologically related lists (e.g., fat, cab, sat, for the critical lure cat; Sommers \& Lewis, 1999) and recently Finley, Sungkhasettee, Roediger, and Balota (2017) found that hybrid lists of conceptual and phonological items produced higher false memory rates than purely conceptual lists.

The main evidence that either supports or refutes the perceptual priming hypothesis for critical lures comes from data in priming tasks including the stem completion task (Hicks \& Starns, 2005; McDermott, 1997; McKone \& Murphy, 2000), the fragment completion task (McDermott, 1997), the anagram task (Lövdén \& Johansson, 2003), the lexical decision task (McKone, 2004; Tse \& Neely, 2005, 2007) and perceptual identification of degraded words (Hicks \& Starns, 2005; Otgaar et al., 2015), all of which concern completing/identifying a word, (i.e., verbal in nature). We argue that there are two possible confounding factors in this previous research. First, the nature of these verbal priming tasks (perceptual vs. conceptual) is controversial in that some consider the stem completion task as conceptual not perceptual (Brown \& Mitchell, 1994; Horton, Wilson, \& Evans, 2001). Indeed, research has found that articulatory (verbal) suppression mediated critical lure priming in the stem completion task and in the anagram task (Lövdén \& Johansson, 2003; Van Damme, Menten, \& d'Ydewalle, 2010). For instance, when participants repeatedly said out loud the word "Coca-Cola" during encoding of DRM lists, critical lure priming disappeared. This suggests that verbal "perceptual" tasks might have a conceptual component, as purely perceptual tasks should not be affected by verbal suppression (Van Damme, Menten, \& d'Ydewalle, 2010). To examine the nature of critical lures' memory traces, an unambiguous perceptual task needs to be used. Second, for verbal stimuli (i.e., words), it is difficult to completely dissociate perceptual information from conceptual meanings as words themselves usually constitute meanings (e.g., Can you communicate the meaning of 
"hot" without the word hot?). Thus, verbal stimuli might not be the best way to study the perceptual/conceptual nature of false memories' mental representations.

\section{The Present Study}

To deal with the above concerns, the present study used picture stimuli and a pictorial perceptual closure task to explore the consequences of false memories for visual stimuli and to test the perceptual/conceptual nature of false memories' mental representations. In Experiment 1, we evoked false memories for pictures by presenting pictorial versions of the DRM lists (see Israel \& Schacter, 1997). Then, participants completed a recognition test to measure their false memory levels. Finally, participants received the pictorial PCT in which they were asked to identify degraded pictures of the studied (true) items as well as the critical lures as quickly as possible. Experiment 1 examined what consequences visual false memories might have on the identification performance of the PCT. In line with recent findings of the positive consequences of verbal false memories (Howe et al., 2010, 2011, 2013, 2015, 2016; Otgaar et al, 2015), one might expect to find that visual false memories are more easily recognized than visual true memories on the PCT. However, predictions can be made based on contrasting hypotheses about the nature of mental representation of false memories for visual stimuli. According to the dual coding theory, true memories for pictures are stored as both imaginal (perceptual) and verbal (conceptual) representations (Paivio, 1991). For instance, after seeing an image of a car, people will encode perceptual details such as shape and color of the car and they will also encode the concept "car", which is verbal or linguistic. If false memories for visual stimuli also contain imagery representations, critical lure images should prime the pictorial PCT as fast as studied pictures. Conversely, if false memories for pictures are not perceptually based, false memories for visual stimuli might not prime the PCT as fast as presented pictures. In Experiments 2 and 3, we tested whether false memories for visual stimuli are conceptual (i.e., in a verbal form) in 
nature. We manipulated the modality of the study phase (picture vs. word) and modality of the PCT (picture vs. word). If false memory activations for critical pictures are conceptual, false memories for pictures should have a priming effect on the verbal PCT (i.e. identifying words).

\section{Experiment 1}

Before conducting Experiment 1, we conducted a pilot experiment with an identical procedure as in the current experiment. Based on the results from the pilot experiment, we have achieved effect sizes to estimate the sample size of Experiment 1 and we have obtained materials that are suitable for testing our hypotheses (for details see the supplementary materials).

\section{Method}

\section{Participants}

Based on the data from the pilot experiment (see supplementary materials), the Cohen's $d$ between the studied items and critical lures was from $0.52 \sim 0.76$. To determine the sample size, we estimated the effect size as medium $(d=0.5)$. Using the software G*Power 3.1 (Faul, Erdfelder, Lang, \& Buchner, 2007), power analysis showed that thirty-four participants were needed when $d$ was estimated as 0.5 and power was estimated as 0.80 . Forty-five participants took part in this experiment. One participant was excluded due to misunderstanding of the instructions. Out of the 44 participants left, 6 were males and 38 females $\left(M_{\text {age }}=22.39, S D=\right.$ 5.59) with age ranging from 19 to 54 years old. They received credit points or a financial compensation (€7.50). The experiment was approved by the ethical committee of the Faculty of Psychology and Neuroscience, Maastricht University.

\section{Materials}

Study phase. In the current experiment, nine DRM wordlists that could be represented pictorially were chosen from Peters, Jelicic, and Merckelbach (2015). Each DRM list included 
eight associated words (e.g., truck, bus, train, jeep, etc.) and these words were all related to a non-presented target or "critical lure" (i.e., car). In this experiment, we used pictorial versions of the DRM words (see also Israel \& Schacter, 1997; Schacter, Israel, \& Racine, 1999). The pictures were collected by means of a Google Images search. For example, for the word "truck", we searched for a picture of a "truck" using the Google Image search engine. All pictures were showing objects in the center (e.g., car, bread, pen) with a white background (see Appendix A for the DRM lists). To have a rough index that our chosen studied items and critical lures did not differ on certain critical dimensions, we looked at the following issues. First, we obtained the concreteness ratings ( 1 to 7$)$ for the DRM list words $(M=6.0, S D=0.55)$ and critical lures $(M=$ 5.7, $S D=0.88$ ) from Nelson, McEvoy, and Schreiber (1998) and found no significant difference between list words and critical lures $(p>.05)$. Second, for the pictures of the DRM lists and critical lures, we asked a pilot sample of participants $\left(n=11, M_{\mathrm{age}}=24.1, S D=4.66 ; 55 \%\right.$ female) to name the objects in the pictures. $96.34 \%$ of the DRM pictures and $99.5 \%$ of the critical lure pictures were named correctly. Collectively, these analyses showed that our visual stimuli were concrete enough to be identified and would not lead to multiple interpretations. The pictures were presented digitally for $1000 \mathrm{~ms}$, with $1000 \mathrm{~ms}$ inter-stimulus interval using E-Prime 2.0 software. Pictures within each list were presented in descending associative order.

Recognition test. The recognition test included 72 pictures in total. Of these pictures, 36 pictures were presented in the study phase (e.g., pictures of truck, bus, train, etc.; four randomly selected pictures per list), 9 were pictures of critical lures (e.g., image of car), 9 were not presented but related pictures (e.g., image depicting bicycle) and 18 were not presented and unrelated pictures (e.g. pictures of tree, washing machine, glasses, etc.). Each picture was shown briefly for $100 \mathrm{~ms}$ and there was a fixation cross on screen lasting $1500 \mathrm{~ms}$ after each picture. 


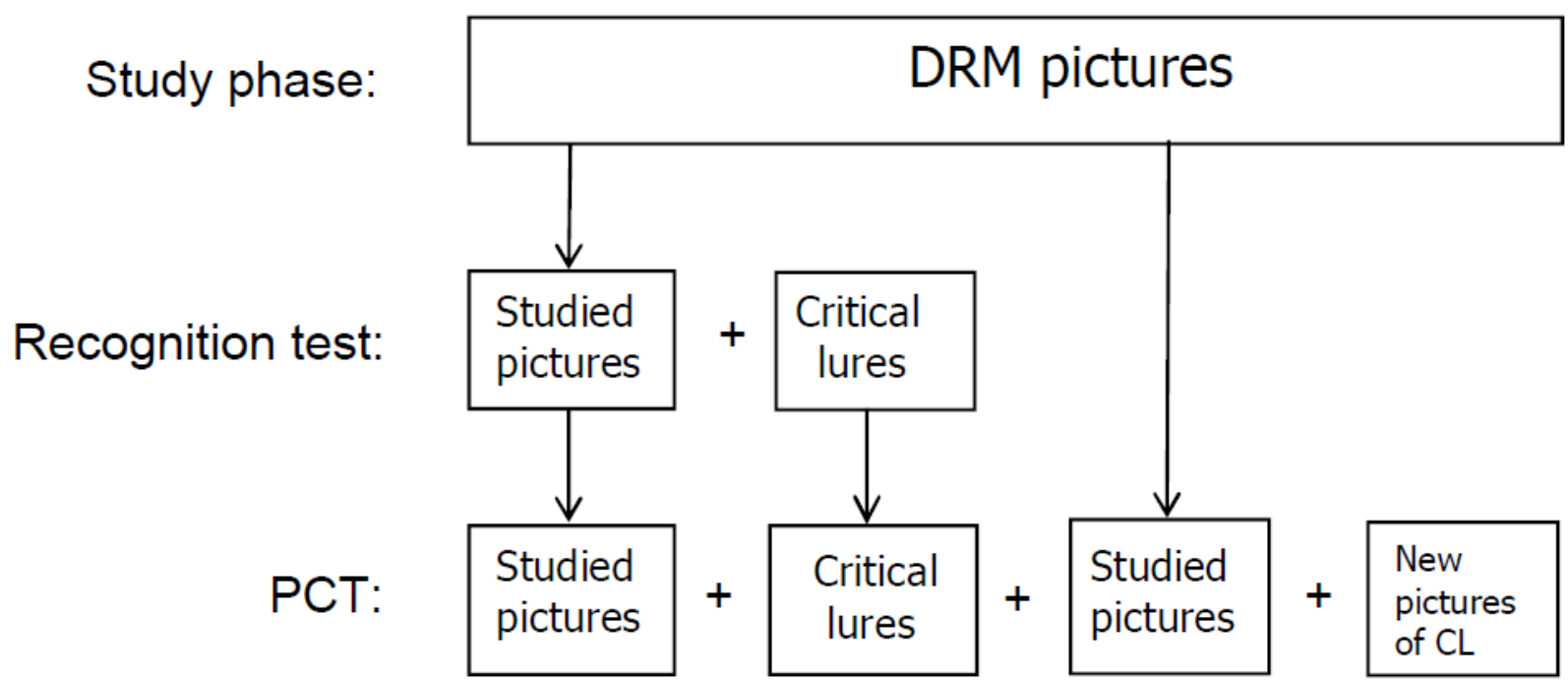

Figure 1. Diagram of procedure (CL: Critical Lures).

Perceptual closure task. The perceptual closure task (PCT) contained 108 pictures. Of all these pictures, 72 were studied pictures ( 36 were shown in the recognition test and 36 were not), 9 were pictures of critical lures from the recognition test, 9 were new pictures of the critical lures and 18 were unrelated pictures ( 9 were from the recognition test and 9 were not). As Figure 1 shows, for each kind of memory type (studied items, critical lures, unrelated), half of the pictures were shown during the recognition test and the other half was not. For instance, there were two sets of pictures for the critical lures. One set ( 9 pictures) were shown in the recognition test, the other set ( 9 new pictures of the critical lures) were not included in the recognition test but were tested directly in PCT (see Figure 1). For the 72 studied pictures, half were presented both in the DRM lists and in the recognition test while the other half were only shown in the DRM lists but not included in the recognition test. The pictures were displayed with a distortion filter that enabled the pictures to become clearer over time. We included 9 gradual gradations of blur, and the last one was the original picture (see Appendix B). Each blur was presented for 1 second and participants were asked to respond within 10 seconds. This task provides measures of both the 
accuracy and the reaction times for the identification of the pictures using the software E-Prime 2.0. The distorted pictures were created using GIMP 2.0.

\section{Design and Procedure}

A 3 (Memory type: studied items, critical lures, unrelated) $\times 2$ (Recognition presentation: yes vs. no) within-subject design was used. Because the PCT is a priming task, the mere presentation of pictures in the recognition test might confound the results (but see Otgaar et al., 2015). In order to control the possible priming effect from the recognition test, a random half of the studied pictures in the PCT were presented in the recognition test and the other half were not shown during the recognition test. For the critical lures in the PCT, two versions of pictures for the same critical lure were prepared; one version was presented in the recognition test and the other was not. It was the same manipulation with unrelated pictures that half of the unrelated pictures were included in the recognition test and the other half were only shown during the PCT.

Participants were tested individually for approximately 45 minutes in lab facilities. First, participants were shown 9 pictorial DRM lists, with order of the lists randomized. Participants were instructed to memorize each picture and think about the concept of the picture when they saw it on the screen. After the presentation of all pictures, participants played Tetris for 5 min (filler task). Next, participants received the recognition test, during which pictures were subsequently presented and participants were asked to answer "yes" or "no" in a pop-up window to indicate whether they had seen the picture before or not. Finally, following five minutes of the filler task, participants received the perceptual closure task. They were asked to press the space bar as soon as they recognized the blurred picture. After pressing the button, a window popped up and asked participants to type in what they thought represented the degraded picture. No feedback was given regarding whether they had answered correctly or not. The pictures were 
successively presented in a pseudo- random order. Input results and reaction times were measured by the E-Prime 2.0 software.

\section{Results and Discussion}

The mean recognition rate for all studied pictures was $90.97 \%(S D=9.15)$. The mean false recognition rate for critical lures was $26.83 \%(S D=14.48)$, which is consistent with previous research using visual stimuli to induce false memories (see Israel \& Schacter, 1997; Koutstaal, Schacter, \& Brenner, 2001). Mean false recognition rate for unrelated items was $1.48 \%(S D=$ $3.80)$.

Before analyzing the data from the perceptual closure task, we filtered the data based on the following criterion (see also Otgaar et al., 2015). First, for studied pictures, we only included the reaction times for pictures that participants had recognized in the recognition test. This is to make sure they had formed true memories for these pictures. Second, for critical lures, only when participants falsely recognized the critical lures as presented during the recognition test were the reaction times for these pictures included in the analysis. This again, is to make sure they had formed false memories for the critical lure pictures. The above two criteria did not apply to pictures in the "no recognition presentation" condition as those pictures were not included in the recognition test. Third, pictures that were not identified correctly in the PCT were removed. This applied to all studied pictures, critical lures and unrelated items. For instance, if a participant pressed the button indicating identification of a picture (e.g., butter) but then did not write an answer or filled in an incorrect response (e.g., chocolate), then this was removed from the analyses. However, synonyms of the answers were accepted. For example, if a participant answered marmalade for a picture depicting jam, the answer was also counted as correct. Less than $5 \%$ of the accepted answers were synonyms. Of a total of 3484 answers that could be provided, $91.8 \%(N=3200)$ were correct and $8.2 \%$ were blank or incorrect $(N=284)$. 
We conducted a 3 (Memory type: studied items, critical lures, unrelated) $\times 2$ (Recognition presentation: yes vs. no) repeated measures ANOVA to examine the PCT reaction time differences of the different memory types. Missing data ( 9 out of 264 cases) were replaced by the average value in the corresponding condition. As Figure 2 shows, no statistical interaction effect was found, $F(2,86)=1.63, p=.201, \eta_{\text {partial }}^{2}=.04$. There was a statistically significant main effect of memory type, $F(2,86)=27.51, p<.001, \eta^{2}$ partial $=.39$. Post-hoc Bonferroni tests revealed that studied items $(M=3011.63, S E=73.83)$ were identified statistically faster than critical lures $(M=3857.33, S E=136.89 ; p<.001)$ and unrelated items $(M=3678.92, S E$ $=116.82 ; p<.001)$, and the latter two did not differ from each other $(p=.718)$. We also found a significant main effect of recognition presentation, $F(1,44)=12.09, p=.001, \eta^{2}$ partial $=.22$.

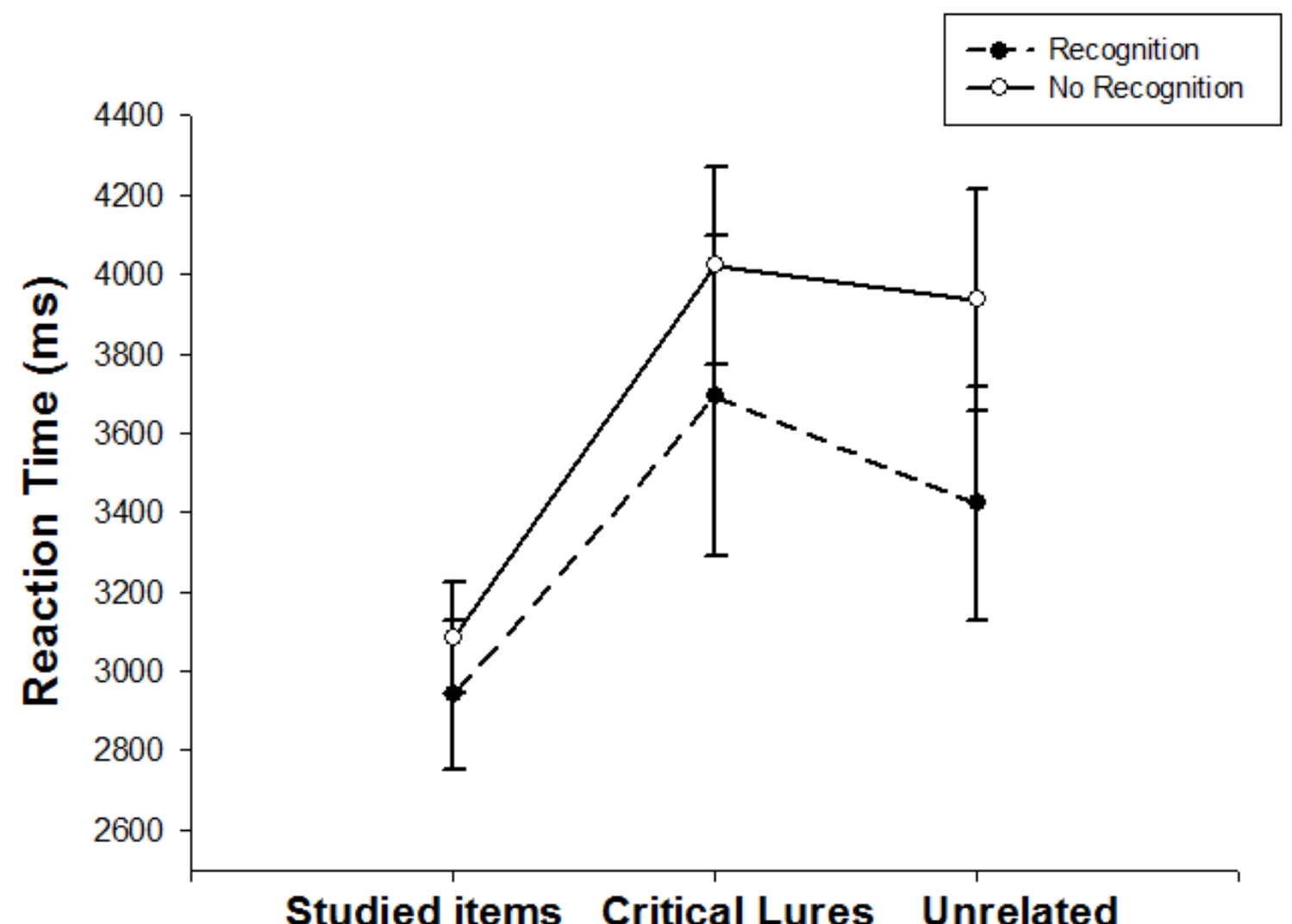

Figure 2. Mean reaction times in different Memory type and Recognition presentation conditions. Error bars indicate 95\% confidence intervals (Experiment 1). 
In the present experiment, we found that studied pictures (true memories) served as better primes for the PCT than false memories and the latter did not differ from unrelated pictures. That is, when participants were presented on the PCT with a picture of a non-presented critical item, they were statistically slower in identifying it than when they were presented with studied pictures. When using verbal stimuli (i.e., words), we and others (Howe et al., 2010; Otgaar et al., 2015) have, however, found that verbal false memories can lead to faster performance on tasks such as the PCT. Specifically, in these studies, it was found that false memories and not true memories served as the best primes. The current experiment shows that this finding cannot be translated to visual false memories or false memories that share more the characteristics of everyday experiences (e.g., color, details, etc.). False memories for pictures might not retain perceptual information like true memories do.

Our results on false recognition rates are in line with research on the mechanisms behind false recognitions for visual stimuli. In the current experiments, each picture was a visual analogue of a list member from the DRM list. Although pictures within one DRM list shared semantic relatedness with each other, each picture had distinctive perceptual characteristics. For instance, an image of a car differed in shape, color, and other details with a truck. Distinctive perceptual information is known to attenuate false memory and results in fewer pictures being false recognized (Arndt \& Reder, 2003; Howe, 2008). We also found that stimuli presentation during recognition test improved reaction speed in the later identification task than when stimuli were not presented during the recognition test. However, stimuli exposure in the recognition test did not confound the priming effect of memory type. 
Overall, we found that false memories for visual stimuli were less efficient primes on the PCT than visual true memories. We achieved the same results in our pilot experiment (see supplementary materials). The results led us to question the nature of mental representations of false memories induced by pictorial DRM lists. If false memories for pictures contain imagery representations as true memories do, retention of false memories should prime the identification of those images. Results from the current experiment did not support this hypothesis.

One might argue that the slower identification times for critical lure pictures were caused because studied pictures were presented more often (i.e., one time extra during the study phase) than critical pictures which were only presented during the test phase. To examine this hypothesis, we compared studied items that were not included in the recognition test (exposed once) with critical lures that were in the recognition test (also exposed once), and we found that critical lures were still more slowly identified than studied items, $t(43)=3.43, p<.001$ (see Figure 2). We also looked at the studied items that were only shown in the study phase (exposed once) and studied items that went through both study phase and recognition test (exposed twice). There was no significant difference in PCT performance, $t(43)=1.96, p>.05$, indicating no effect of test on PCT performance. These analyses ruled out the possibility that our effects were due to the frequency of stimuli exposure. The most plausible explanation would be that mental representations for false memories derived from pictorial DRM lists are not visual, but verbal in nature. We suggest that false memories elicited by pictorial DRM lists are purely conceptualnot pictures but words in the mind's eye.

According to spreading-activation theories (Howe et al., 2009; Roediger et al., 2001), presentation of DRM words activates corresponding concept nodes and this activation automatically spreads to interrelated nodes. Thus, non-presented but related concepts could be erroneously activated at the encoding phase. When it comes to presenting pictures of DRM list 
members, visual sensory traces are encoded for studied pictures and at the same time corresponding concepts of the pictures are activated automatically (based on the dual coding theory); however, such activation of the list members might only spread along the conceptual network as the DRM list members are semantically related instead of perceptually related. As a result, concepts of critical lures are activated and pictures of critical lures are falsely recognized during a recognition test. However, the activation of critical lure concepts might not work on the priming of critical lures for pictures. Previous studies have demonstrated the priming effect of false memories for verbal stimuli (McDermott, 1997; Otgaar et al., 2015; Tajika et al., 2005). The discrepancy between previous studies and our study led us to conduct a second experiment where we orthogonally manipulated the modality (picture vs. word) of both the DRM stimuli and the PCT. We aimed to test the hypothesis that mental representations of critical lures based on pictorial stimuli are conceptual, not perceptual or imaginal, in nature.

\section{Experiment 2}

The purpose of Experiment 2 was to examine the priming effect of false memories for both visual and verbal stimuli on the PCT in one study. Previous study showed that verbal false memories primed the verbal PCT faster than true memories (Otgaar et al., 2015). Our prediction was that we would find this effect in Experiment 2 and we predicted that the reverse was true for false memories for visual stimuli, i.e. false memories for visual stimuli primed the PCT slower than true memories. More importantly, we were interested in whether false memories for visual stimuli have priming effects on identification of words. Experiment 2 was an orthogonal design with manipulation of verbal vs. visual modalities on both study phase and the PCT.

\section{Method}

\section{Participants}


The Cohen's $d$ between studied items and critical lures was 0.68 in the recognition presentation condition and 1.42 in the no recognition presentation condition in Exp. 1. Again, we were interested in the reaction time contrast between studied items and critical lures in each group. We estimated $d=0.7$ and power as 0.8 , G. Power analysis showed nineteen participants were needed in each group and thus 76 participants were needed in total. Eighty participants were tested in Experiment 3. The mean age of the sample was 20.6 years old $(S D=2.20$; age range $=$ 18 to 29 years old). There were 8 males and 72 females. They received credit points or a financial compensation $(€ 7.50)$.

\section{Materials}

Study phase. The nine DRM lists (eight-item per list) from Experiment 1 were used. However, Experiment 2 used two sets of stimuli: verbal DRM words and pictorial version of the verbal DRM lists. The pictorial version was exactly the same as used in Experiment 1.

Recognition test. Recognition items were the same as in Experiment 1, except in Experiment 3 a verbal version of the recognition items was used as well. In the verbal version, each word (e.g., sandwich) was a corresponding concept to a picture in the pictorial version (e.g., a picture of a sandwich).

Perceptual closure task. The PCT had two versions, a word version and a picture version. The two versions contained the same conceptual items of studied and critical items, only with different presentation forms. For instance, the item "car" in the word version of the PCT was the word car, while in the picture version was a picture of a car. The filtering parameters (level of degrading) for words were the same as the filters for pictures in Experiment 1. The word version of the PCT included 99 words, consisting of 72 studied words ( 36 were shown in the recognition test and 36 were not), 9 critical lures, 9 related words and 9 unrelated words. The picture version of the PCT was composed of 99 pictures, including 72 studied pictures (36 were shown in the 
recognition test and 36 were not), 9 pictures of critical lures from the recognition test, 9 new pictures of the critical lures and 9 unrelated pictures.

\section{Design and Procedure}

Experiment 2 involved a 2(DRM modality: picture vs. word) x 2(PCT modality: picture vs. word) x 3(Memory: studied items, critical lures, unrelated items) mixed design where the first and second factors were between-subjects and the third factor was within-subject. Participants were tested individually for approximately 40 minutes in lab facilities. The procedure was exactly the same as in Experiment 1, but we manipulated the stimuli modality (picture vs. word) in the study phase and in the PCT phase. Thus, we had four groups: (1) picture-picture group, where DRM lists were presented in a pictorial form in the study phase and blurred pictures had to be identified in the PCT; (2) picture-word group, where pictorial DRM items were presented but blurred words for these items had to be identified in the PCT; (3) word-word group, words were presented and later identified in the PCT; and (4) word-picture group, where DRM words were presented in the study phase and then pictorial forms had to be identified in the PCT. Participants were randomly assigned to one of the four groups. To be noted, the modality of the recognition test was always consistent with the study phase.

\section{Results and Discussion}

The mean recognition rates in different groups of participants are shown in Table 1. Eighty participants were equally distributed in the four groups. Inspection of Table 1 shows that when the DRM lists were presented verbally, the false recognition rates for critical lures were higher than when they were presented pictorially $(F(1,78)=40.88, p<.001)$. However, this

discrepancy is not a confounding factor to the PCT results. This is because the data analysis is not contingent on differences in true or false memory rates, just that a true or false memory had been generated during the recognition test (i.e., we only analyse the PCT data for which true or false 
recognition occurred). Before analyzing the data from the $\mathrm{PCT}$, we conducted the same filtering process as in Experiment 1. That is, first, we focused only on the reaction times of recognized studied and critical items and then, within these recognized items, items with incorrect answers were removed from the analysis. Of a total of 2595 recognized items, for $10.8 \%(N=280)$ items participants failed to identify them within $10 \mathrm{~s}$, thus no answers and reaction times were recorded by the program; for $5.4 \%(N=141)$ of the items, participants provided incorrect answers, of which the reaction times were removed from analysis. Incorrect answers in unrelated items were also removed. Of a total of 720 unrelated items, participants failed to identify $14.6 \%(N=105)$ of the items, and answered incorrectly for $11.1 \%$ of the items $(N=80)$. Those items were not included in analysis.

Table 1. Mean recognition rates for studied items, critical lures and unrelated items in four groups of participants ( $n$ : number of participants in that condition).

\begin{tabular}{lllll}
\hline & $\begin{array}{l}\text { Picture-Picture } \\
(n=20)\end{array}$ & $\begin{array}{l}\text { Picture-Word } \\
(n=20)\end{array}$ & $\begin{array}{l}\text { Word-Picture } \\
(n=20)\end{array}$ & $\begin{array}{l}\text { Word-Word } \\
(n=20)\end{array}$ \\
\hline Studied items & $87.86 \%$ & $87.14 \%$ & $77.43 \%$ & $79.14 \%$ \\
Critical lures & $26.11 \%$ & $23.89 \%$ & $52.22 \%$ & $50.00 \%$ \\
Unrelated items & $1.11 \%$ & $0.56 \%$ & $6.11 \%$ & $3.89 \%$ \\
\hline
\end{tabular}

The main interest was to compare PCT reaction times to studied items and critical lures in each group, so we conducted a 4(Group: picture-picture, picture-word, word-picture, word-word) x 3(Memory: studied items, critical lures, unrelated items) repeated measures ANOVA, with Group as a between-subjects variable. Because Experiment 1showed that stimuli exposure in the recognition test did not interact with the reaction time contrast among studied items, critical lures and unrelated items, the items for which reaction times were analyzed below were all presented in the recognition test. Missing data (4 out of 240 cells) were replaced by the average value in the corresponding condition. A statistically significant interaction effect between Group and Memory was found, $F(6,152)=8.01, p<.001, \eta_{\text {partial }}^{2}=.24$ (see Figure 3$)$. There was a main effect of 
Memory, $F(2,152)=19.25, p<.001, \eta^{2}{ }_{\text {partial }}=.20$, and a main effect of Group, $F(3,76)=3.86, p$ $=.013, \eta_{\text {partial }}^{2}=.13$. Simple effect analyses indicated the following: (1) in the picture-picture group, studied items $(M=3268, S D=676)$ primed the PCT significantly faster than critical lures $(M=4069, S D=1815 ; p=.047$, Cohen's $d=0.57)$ and unrelated items $(M=3558, S D=780 ; p=$ .03 , Cohen's $d=0.55$ ), and the latter two did not differ from each other $(p=.25)$, which is consistent with findings in Experiment 1; however, (2) critical lures $(M=3595, S D=848)$ primed the PCT significantly faster than studied items $(M=4309, S D=635)$ in the picture-word group ( $p$ $<.001$, Cohen's $d=0.99)$, and both were statistically faster than the unrelated items ( $M=5027$, $S D=517 ; p \mathrm{~s}<.001$, Cohen's $d_{\text {studied items }}=1.40$, Cohen's $\left.d_{\text {critical lures }}=2.28\right)$; (3) in the wordpicture group, critical lures $(M=3731, S D=1073)$ and studied items $(M=3873, S D=567)$ did not differ from each other $(p=.58)$, and both did not differ from unrelated items $(M=4217, S D=759$; $p \mathrm{~s}>.05)$ in priming the PCT; and (4) in the word-word group, critical lures $(M=3228, S D=904)$ were significant faster primes than studied items in the PCT $(M=3720, S D=716 ; p=.02$, Cohen's $d=0.62)$, and both were faster than unrelated items ( $M=4622, S D=747 ; p \mathrm{~s}<.001$, Cohen's $d_{\text {studied items }}=1.31$, Cohen's $d_{\text {critical lures }}=1.68$ ), which replicated the findings by Otgaar et al. (2015). 


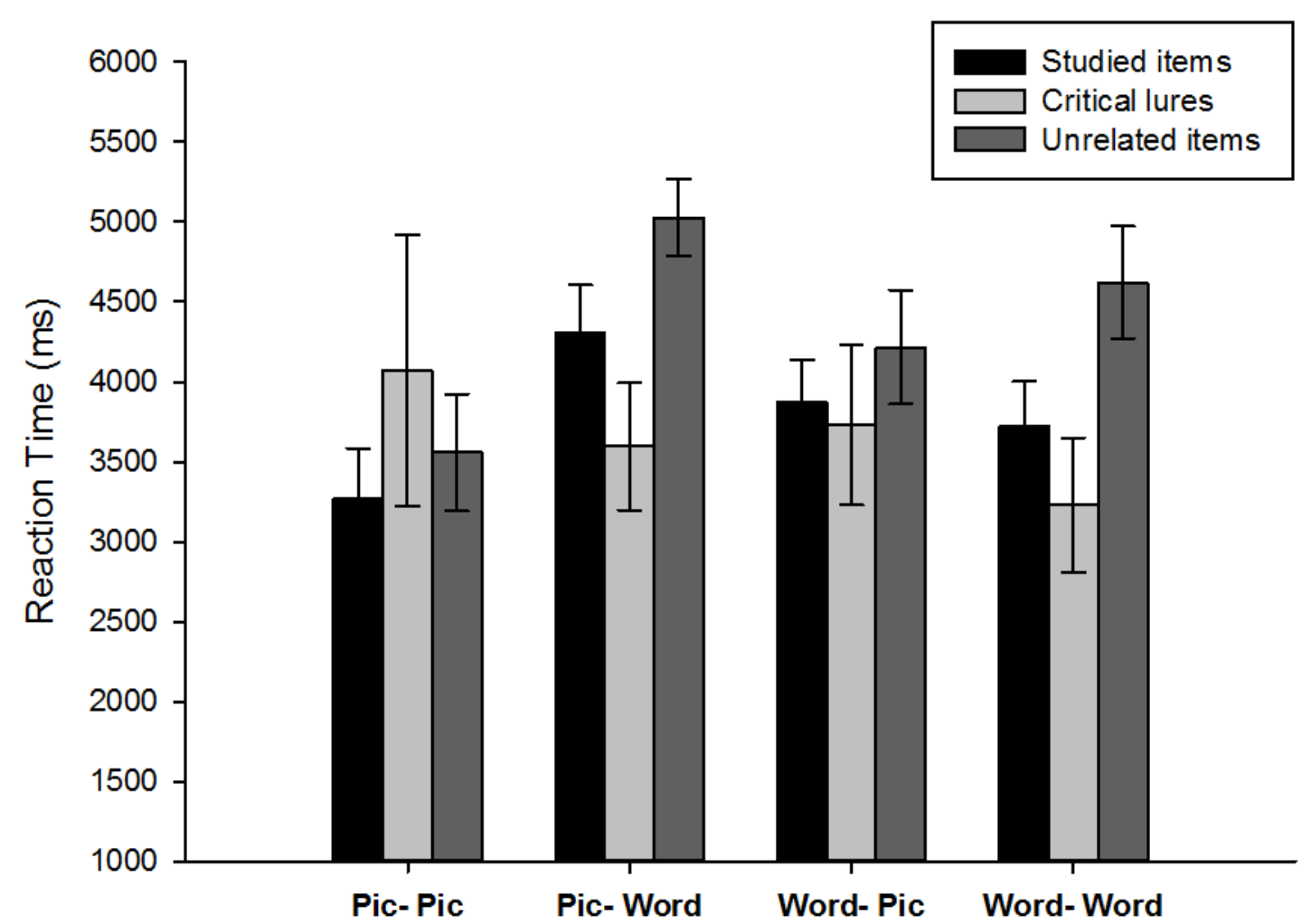

Figure 3. Mean reaction times to studied items, critical lures and unrelated items in different study/PCT modalities ("Pic" stands for "Picture"). Error bars indicate 95\% confidence intervals (Experiment 2).

Experiment 2 replicates the results of Experiment 1 that false memories induced by pictorial DRM lists primed the pictorial PCT slower than true memories did, and they were no significantly different from unrelated pictures. Participants falsely recognized critical lure pictures as studied in the recognition test, however false memory activation did not have any facilitation on identifying critical lure pictures. Memory activation of studied pictures, on the other hand, improved the speed in the identification of studied pictures. Experiment 2 also replicates the finding by Otgaar et al. (2015) that verbal false memories induced by verbal DRM 
lists had a priming effect on the PCT, and this effect was even more superior than that of verbal true memories.

Experiment 2 also provided two new findings. First, we found that both false and true memories induced by pictorial DRM lists had a priming effect in the verbal PCT, and the magnitude of false memories' priming effect was larger than that of true memories for pictorial DRM lists. This result pattern is the same as in the word-word condition in this experiment, where verbal DRM lists were presented and verbal PCT was completed. It can be best explained by the assumption that false memories elicited by DRM pictures are verbal in nature. When pictures of DRM items were presented, concepts of these items were activated and spread to nearby concepts, i.e. critical lures, in a semantic network. The activation of critical lure concepts later facilitated the identification of critical lure words. If DRM pictures created visual false memories (i.e. vivid imagery representations of critical lure pictures), then visual false memories should have a priming effect in the pictorial PCT, which was not found in our two experiments. Thus, false memories from pictorial DRM lists should be encoded in other forms, and the PictureWord dataset in Experiment 3 supports the verbal form.

Second, we found that in the word-picture condition, where DRM words were presented and pictorial forms were identified in the PCT, neither false memories nor true memories had a priming effect. This is logical as in the study phase both verbal true memories and verbal false memories were created. According to the spreading-activation theories, conceptual nodes for studied items and critical lures are embedded in one semantic network and are both activated during study, which means the encodings of true and false memories are both verbal. As a result, verbal true memories and verbal false memories should not prime identification of pictures in the PCT. 
A limitation of Experiment 2 is that we asked participants to think about the concepts of the pictures during the presentation of pictorial DRM lists. This instruction was borrowed from Israel and Schacter (1997) in order to maximize the chances of obtaining false memories of critical lures within the DRM paradigm. Nevertheless, it might have switched participants' attention from viewing the pictures to conceptually processing the pictures. Experiment 3 was conducted to rule out this possible confounding factor. Here, participants were merely asked to carefully view the presented pictures/words during the study phase of Experiment 3. Moreover, data on Image Agreement Ratings (Snodgrass \& Vanderwart, 1980) of stimuli were obtained and reported in Experiment 3.

\section{Experiment 3}

\section{Method}

\section{Participants}

An a priori sample size estimation was conducted as per Experiment 2, and suggested that at least 76 participants were necessary. We tested 84 participants in Experiment $3\left(M_{\text {age }}=20.18, S D\right.$ $=2.76$; age range $=18$ to 40 years old; $83 \%$ female). Participants received credit points for participation in the experiment.

\section{Materials}

The same verbal and pictorial DRM lists (eight-item per list) from Experiment 2 were used. For the orientation of the DRM pictures, we used: (1) objects standing in their natural (vertical) positions if possible (the car list, the bread list, the fruit list, the shirt list, the cup list, the chair list and the foot list); (2) long, thin objects that cannot stand (the needle list and the pen list) oriented at 45 degree angle (upper right to lower left). Critical lure pictures were always in the same orientation with most members of the corresponding studied list. We administered an Image Agreement Ratings questionnaire to 43 participants $\left(M_{\text {age }}=20.19, S D=1.97 ; 88 \%\right.$ female $)$, 
asking them to rate to what extent the DRM picture represents their mental image of the DRM word on a 1 to 5 scale $(1=$ no agreement; $5=$ high agreement $)$. Of 54 pictures whose PCT data would be entered into data analysis, three pictures (two studied pictures and one unrelated pictures) had an average imagery agreement rating lower than 3. Thus, PCT data of these three pictures were not entered into analyses. After removing these three pictures, a repeated measures ANOVA was conducted to compare the mean imagery agreement ratings among studied pictures $(M=4.22, S D=0.48)$, critical pictures $(M=4.23, S D=0.54)$ and unrelated pictures $(M=4.25$, $S D=0.46$ ). No statistical difference on imagery agreement ratings was found among different type of stimuli, $F(2,84)=0.16, p=.85, \eta^{2}$ partial $=.004$

\section{Design and Procedure}

Experiment 3 used the same 4 (Group: picture-picture, picture-word, word-picture, and word-word) x 3 (Memory: studied items, critical lures, unrelated items) mixed design as in Experiment 2, where Group was between-subjects and Memory was within-subject. The procedure was identical to that of Experiment 2, except the instruction in the study phase was modified such that in Experiment 3 participants were merely asked to view the pictures carefully.

\section{Results and Discussion}

Mean recognition rates of studied items and critical lures in different groups are shown in Table 2. Participants in Experiment 3 had similar false memory rates for critical pictures $(\sim 35 \%)$ with previous experiments $(25 \% \sim 30 \%)$. This suggests that telling participants to think about the concept of the presented picture or not did not impact false recognition of critical pictures.

Table 2. Mean recognition rates for studied items, critical lures and unrelated items in four groups of participants ( $n$ : number of participants in that condition).

\begin{tabular}{lllll}
\hline & $\begin{array}{l}\text { Picture-Picture } \\
(n=20)\end{array}$ & $\begin{array}{l}\text { Picture-Word } \\
(n=22)\end{array}$ & $\begin{array}{l}\text { Word-Picture } \\
(n=22)\end{array}$ & $\begin{array}{l}\text { Word-Word } \\
(n=20)\end{array}$ \\
\hline Studied items & $87.95 \%$ & $87.00 \%$ & $79.22 \%$ & $74.45 \%$ \\
Critical lures & $35.63 \%$ & $35.86 \%$ & $59.66 \%$ & $40.00 \%$
\end{tabular}


Unrelated items $1.11 \%$

$3.54 \%$

$4.55 \%$

$3.33 \%$

After filtering wrong answers and non-recognized studied items and critical pictures as in previous experiments, a 4 (Group: picture-picture, picture-word, word-picture, word-word) x 3 (Memory: studied items, critical lures, unrelated items) repeated measures ANOVA was conducted, with Group as a between-subjects variable. A statistically significant interaction effect between Group and Memory was found, $F(6,152)=4.26, p=.001, \eta^{2}{ }^{2}$ artial $=.14$. There was a main effect of Memory, $F(2,152)=23.06, p<.001, \eta^{2}{ }_{\text {partial }}=.23$, and a main effect of Group, $F(3,76)=10.84, p<.001, \eta_{\text {partial }}^{2}=.30$.

As can be seen in Figure 4, and verified using simple effect analyses, the following effects were obtained: (1) in the picture-picture group, studied items $(M=3005, S D=444)$ primed the PCT statistically faster than critical lures $(M=3632, S D=1249 ; p=.036$, Cohen's $d=0.65)$ and unrelated items ( $M=3799, S D=830 ; p=.001$, Cohen's $d=0.98)$, and the latter two did not differ from each other $(p=.64)$, which is consistent with findings in Experiments 1and 2; however, (2) in the picture-word group, critical lures $(M=3879, S D=911)$ primed the PCT significantly faster than studied items $(M=4371, S D=548)(p=.005$, Cohen's $d=0.75)$, and both were statistically faster than the unrelated items $(M=5188, S D=462 ; p \mathrm{~s}<.001$, Cohen's $d$ studied items $=1.54$, Cohen's $d_{\text {critical lures }}=1.62$ ), which again replicated results of Experiment 2; (3) in the word-picture group, studied items $(M=3728, S D=450)$ and critical lures $(M=3673, S D=$ 986) did not differ from each other $(p=.81)$, and neither differed from unrelated items ( $M=$ 4081, $S D=890 ; p$ s > .05) in priming the PCT; and (4) in the word-word group, critical lures ( $M$ $=4188, S D=1361)$ and studied items $(M=3672, S D=611)$ did not statistically differ in priming the PCT $(p=.10)$, and both were faster than unrelated items $(M=4678, S D=611 ; p \mathrm{~s}<.05$, Cohen's $d_{\text {studied items }}=1.74$, Cohen's $\left.d_{\text {critical lures }}=0.64\right)$. 


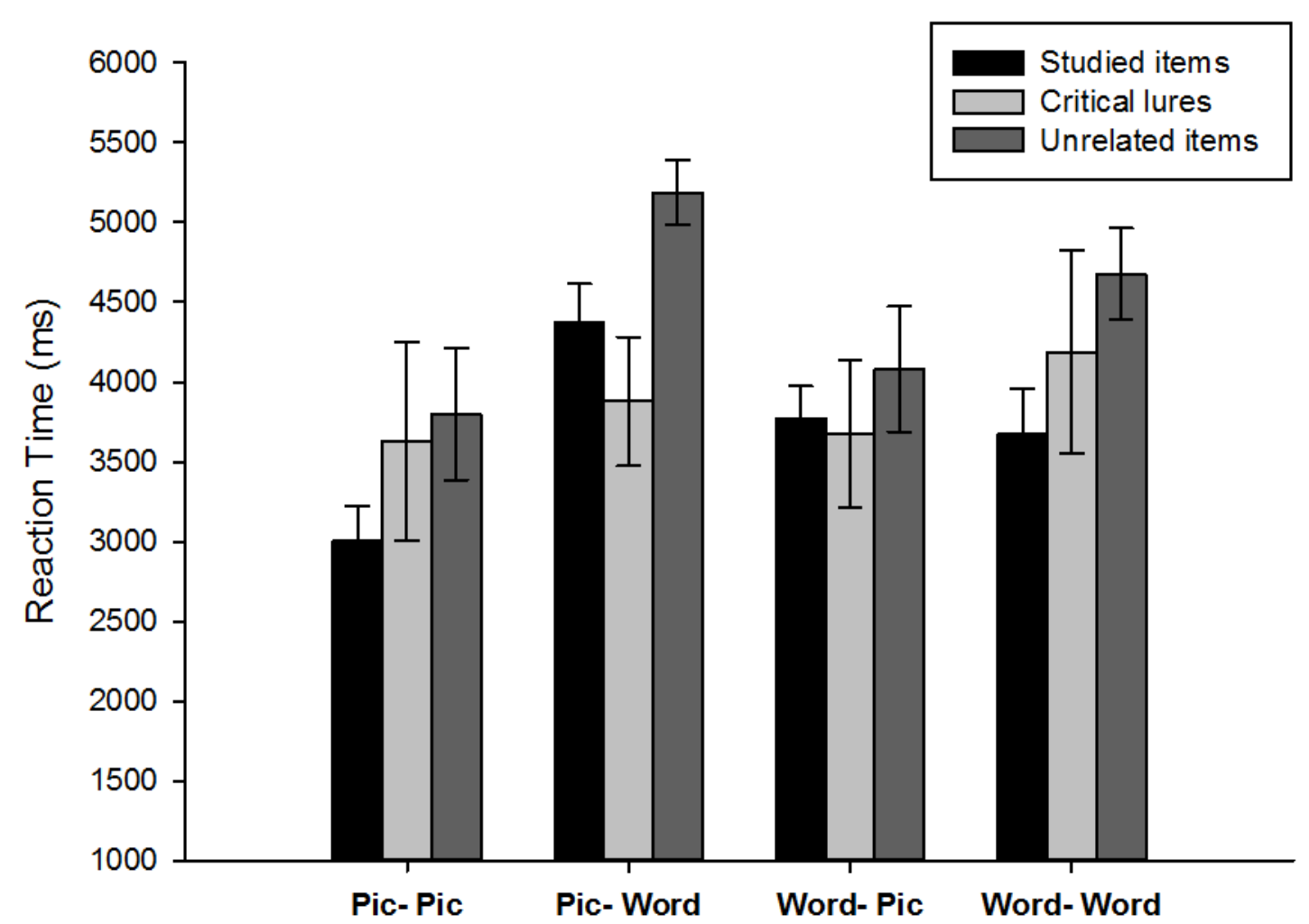

Figure 4. Mean reaction times to studied items, critical lures and unrelated items in different study/PCT modalities ("Pic" stands for "Picture"). Error bars indicate $95 \%$ confidence intervals (Experiment 3).

Experiment 3 replicated the results of Experiment 2. The most relevant results are those of the picture-picture and picture-word groups. In these two conditions of Experiment 3, participants were instructed to view the pictures carefully, which should direct them to perceptually processing the pictures. However, without telling participants to think about the concepts of DRM pictures, false memories of critical pictures still primed identification of corresponding concepts more quickly than true memories of studied pictures (picture-word condition) but lacked a priming effect on identification of the exact same critical pictures (picture-picture condition). The results of Experiment 3 provide converging support for our hypothesis that false memories for visual stimuli are conceptual in nature. 


\section{General Discussion}

Our experiments focused on the consequences of false memories on an adapted perceptual closure task. We investigated the extent to which false memories were better or worse primes on the PCT than true memories. After presenting participants with visual DRM stimuli, the majority formed false memories for non-presented pictures of critical lures. In all four experiments, we found that these false memories did not result in any priming effect in the PCT relative to unrelated pictures, while visual true memories exhibited facilitation in priming the PCT. More specifically, perceptual priming based on visual true memories was faster than that based on false memories for critical lure pictures. However, when we changed the modalities of the study phase and the PCT phase in Experiments 2 and 3, we found that false memories for critical lure pictures resulted in a larger priming effect than true memories in the verbal PCT.

Consistent with the spreading-activation theories, our results support the hypothesis that false memory representations do not contain perceptual information. Although previous studies found that verbal false memories can have priming effects on verbal priming tasks (e.g., the stem completion task, McDermott, 1997; McKone \& Murphy, 2000), these tasks might include a component of conceptual priming and thus, it is not fully justified to interpret them as evidence for perceptual priming for false memories. In fact, Hicks and Starn's (2005) finding of no modality specificity for priming in the stem completion task provides evidence for the conceptual priming in the stem completion task. However, with only verbal priming tasks, Hicks and Starn's study (2005) cannot provide direct evidence regarding whether false memory representation is perceptual or not. By using pictorial stimuli, our study showed that identification of degraded pictures was not facilitated by critical lure pictures, which provides strong and direct evidence for the non-perceptual view of false memory representations. 
We consistently found in three experiments that false memories for pictures primed the PCT more slowly than true memories for pictures. However, in the picture-word group, we found that false memories for pictures had a priming effect in the verbal PCT. To explain the contrasting findings, our interpretation is that memory representations underlying false memories for visual stimuli might be purely verbal or conceptual. Theoretically, this can be explained as follows. The dual coding theory posits that true memories for visual stimuli have two forms of memory coding, imaginal and verbal (Paivio, 1991). In the study phase, true memories for DRM pictures (e.g., a picture of an apple) are encoded as imaginal representations (e.g., image of an apple) as well as verbal representations (e.g., the concept "apple"). The activation of verbal representations is automatic according to the dual-coding theory, and this activation spreads through a semantic network which activates nearby concepts of critical lures (Howe et al., 2009; Roediger et al., 2001). Thus, true memories for visual stimuli are encoded into imaginal and verbal forms while false memories for visual stimuli are only encoded into verbal forms. This interpretation can indeed explain our findings. Since true memories for pictures possess imaginal representations while false memories do not, true memories primed identification of pictures faster than false memories in the pictorial PCT. Since false memories for pictures possess conceptually-based representations like true memories do, critical lure pictures had a priming effect on the verbal PCT.

Interestingly, the above-mentioned explanation is in line with Fuzzy-trace Theory (Brainerd \& Reyna, 2002; Brainerd, Reyna, \& Ceci, 2008). According to the Fuzzy-trace Theory, two independent memory traces, verbatim and gist, are formed when people encode stimuli. Verbatim traces refer to episodic representations of the surface forms of experienced items, which correspond to the perceptual representations. Gist traces are interpretations of concepts (e.g., meanings) that are retrieved from the surface forms, which correspond to the conceptual aspect of 
mental representations. Fuzzy-trace Theory proposes that both verbatim (or perceptual) traces and gist traces contribute to true memories but only gist traces contribute to the formation of false memories. Related to our results, true memories of pictures thus primed identification of both blurred pictures and words while false memories of pictures only primed identification of words.

Our hypothesis is consistent with neuroimaging findings on brain activity differences between true and false memories for visual stimuli. In Slotnick and Schacter's $(2004,2006)$ studies, participants studied sets of exemplar shapes and formed false memories for nonpresented but related shapes. Researchers found that true recognition for images revealed more activities in the early visual cortex compared with false recognition. Stark, Okado, and Loftus (2010) also found stronger activation for visual true memories in early visual processing areas, which are mostly concerned with sensory processing of visual details. Schacter, Chamberlain, Gaesser, and Gerlach (2012) suggest that true memories are accompanied by reactivation of sensory encoding processes that were engaged during the establishment of true but not false memories. We posit that true memory for visual stimuli contain imaginal and verbal representations while false memory for visual stimuli possesses only verbal representations, at least when they are evoked in the DRM paradigm. Activation in early visual areas probably corresponds to the imaginal representation for visual true memory, which can provide a neural basis for the differentiation of memory encoding between true and false memories for visual stimuli.

Another interesting finding is that in the picture-word and word-word conditions, false memories sometimes primed the PCT even faster than true memories. This finding can be explained by the principle of additivity in the spreading-activation theory of false memory. The principle of additivity suggests that activation of the critical lure can summate to produce greater priming effect under multiple sources of activation (e.g., multiple DRM studied items) than under 
a single source of activation (e.g., a studied item) (Roediger et al., 2001; Meade, Hutchison, \& Rand, 2010). That is, during the study phase each concept of the DRM list was probably activated once while the concept of the critical lure had more chance of activating multiple times. Thus, false memories primed the identification of concepts faster than true memories.

The finding of false memories' superior priming effect demonstrates the adaptive nature of memory as well. In recent years, studies have accumulated showing that false memories have adaptive value and can exhibit positive consequences under certain conditions (Howe, 2011; Schacter, 2012). By "positive consequences" it means that false memories show the same efficiency as true memories or even exert more efficiency (i.e., faster identification) than true memories in solving PCT problems. It has been well established by previous studies that verbal false memories can have salutary consequences. Verbal false memories are found to be associated with convergent thinking--a component of creativity (Dewhurst, Thorley, Hammond, \& Ormerod, 2011). Recent studies have confirmed that false memories derived from DRM paradigm solved the PCT faster, solved associative problems faster, and solved analogical problems faster than true memories (Howe, Garner, \& Patel, 2013; Otgaar et al., 2015; Wilkinson, Howe, \& Monaghan, 2018). In our experiments, we replicated previous findings in the word-word group and added another new condition (i.e., picture-word) where false memories exhibit positive consequences as well. Our study suggests that, as long as true and false memories share the same memory activation/representation mechanism (e.g., derived from the same semantic memory network), false memories can have beneficial effects on related tasks (e.g., a semantic associative task).

Some caveats are worth mentioning. In previous studies, participants reported vividly seeing pictures when words were shown and sometimes even seeing pictures that were not shown (Foley, 2012; Foley \& Foy, 2008; Weinstein \& Shanks, 2010). These false memories were 
reported with high confidence and a feeling of recollection. Indeed, false memories are caused by different types of associations (e.g., conceptual, perceptual; Howe et al., 2009; Pesta, Murphy, \& Sanders, 2001). Although our data in the word-picture condition did not support the perceptual priming of words on identifying corresponding pictures, we were using the DRM paradigm in all three experiments, which might be a limitation of our study. For instance, Weinstein and Nash (2013) found perceptual priming for false memories using a visual scene scenario, although they did not control the recognition presentation and their effect size was not large. Moreover, we asked participants to "view the pictures carefully" to guide their attention to perceptually processing the stimuli. Future studies may consider using encoding instructions that focus even more on processing perceptual elements such as color and shape. Further research is needed to examine the underlying representation of false memories by using other false memory paradigms and tasks.

One might ask whether results in our experiments were due to item effects. Data from previous PCT research and data from the current experiments indicate that this is probably not the case. In the verbal PCT study of Otgaar et al. (2015) and associative problem-solving tasks by Howe et al. (e.g., 2010, 2016), the issue of possible item effects has been handled by comparing presented critical lures and non-presented critical lures. These studies still found a priming effect for non-presented critical lures, which is consistent with our results in the word-word condition. As for the results in the picture-picture condition, the pictures in Experiment 1 and our pilot experiment were different stimuli, but we achieved the same results in the two experiments, which eliminates the possibility that our results were due to the use of specific materials. Furthermore, DRM lists in three Experiments were all about familiar objects. We have controlled for the concreteness, name agreement, and image agreement of studied items and critical lures: a pilot name agreement study indicated that both studied pictures and critical pictures were easy to 
identify (both $>96 \%$, see Materials of Exp. 1); and an image agreement ratings questionnaire showed that participants' mental images of DRM items were in high accordance with the pictures used in our experiments ( 4.2 in a 1-5 scale, see Materials of Exp. 3).

Some might argue that the different performance between visual true and false memories on the PCT is due to mere stimuli exposure: studied pictures were presented more often than the critical lures and unrelated pictures (during study phase). What we want to argue here is that we only included reaction times for pictures in which participants responded with "yes" during the recognition test. For studied pictures, only pictures they had recognized in the recognition test were entered into analysis to make sure we were analysing true memories. The same is true for critical lures that only pictures that were falsely remembered were analysed. This means that the comparison level is not stimuli exposure versus no stimuli exposure, but true versus false memory. Furthermore, we examined whether stimuli exposure could explain our effects but we did not find any evidence for this idea. What we want to stress here is that, unlike verbal false memories, false memories for visual stimuli are processed in a way not different from unrelated pictures, and both are more slowly processed than visual true memories. Research on false memories relies heavily on paradigms using verbal stimuli. Studying false memories for stimuli with more ecological validity such as images and events might contribute to a more complete picture of false memory mechanism(s).

To summarize, our experiments provide a first examination of the perceptual priming effect of false memories for visual stimuli in the DRM paradigm. We found that false memories for pictures did not prime identification of degraded pictures, but they had a priming effect on identifying blurred words. Based on these results, we suggest that true and false memories differ in the way they are encoded in that true memories for visual stimuli have both verbal and imaginal memory traces while false memories for visual stimuli are only encoded in a verbal 
form. Our results contribute to a more complete picture about the differentiation between true and false memories and have implications concerning the underlying mechanisms of false memories. 


\section{References}

Arndt, J., \& Reder, L. (2003). The effect of distinctive visual information on false recognition. Journal of Memory and Language, 48, 1-15.

Brainerd, C. J., \& Reyna, V. F. (2002). Fuzzy-trace theory and false memory. Current Directions in Psychological Science, 11, 164-169.

Brainerd, C. J., Reyna, V. F., \& Ceci, S. J. (2008). Developmental reversals in false memory: A review of data and theory. Psychological bulletin, 134, 343-382.

Brown, A. S., \& Mitchell, D. B. (1994). A reevaluation of semantic versus nonsemantic processing in implicit memory. Memory \& Cognition, 22, 533-541.

Deese, J. (1959). On the prediction of occurrence of particular verbal intrusions in immediate recall. Journal of Experimental Psychology, 58, 17-22.

Dewhurst, S. A., Thorley, C., Hammond, E. R., \& Ormerod, T. C. (2011). Convergent, but not divergent, thinking predicts susceptibility to associative memory illusions. Personality and Individual Differences, 51, 73-76.

Faul, F., Erdfelder, E., Lang, A.-G., \& Buchner, A. (2007). G*Power 3: A flexible statistical power analysis program for the social, behavioral, and biomedical sciences. Behavior Research Methods, 39, 175-191.

Finley, J. R., Sungkhasettee, V. W., Roediger, H. L., \& Balota, D. A. (2017). Relative contributions of semantic and phonological associates to over-additive false recall in hybrid DRM lists. Journal of Memory and Language, 93, 154-168.

Foley, M. A., Bays, R. B., Foy, J., \& Woodfield, M. (2015). Source misattributions and false recognition errors: Examining the role of perceptual resemblance and imagery generation processes. Memory, 23, 714-735. 
Foley, M. A., \& Foy, J. (2008). Pictorial encoding effects and memory confusions in the DeeseRoediger-McDermott Paradigm: Evidence for the activation of spontaneous imagery. Memory, 16, 712-727.

Hicks, J. L., \& Starns, J. J. (2005). False memories lack perceptual detail: Evidence from implicit word-stem completion and perceptual identification tests. Journal of Memory and Language, 52, 309-321.

Horton, K. D., Wilson, D. E., \& Evans, M. (2001). Measuring automatic retrieval. Journal of Experimental Psychology: Learning, Memory, and Cognition, 27, 958-966.

Howe, M. L. (2006). Developmentally invariant dissociations in children's true and false memories: Not all relatedness is created equal. Child Development, 77, 1112-1123.

Howe, M. L. (2008). Visual distinctiveness and the development of children's false memories. Child Development, 79, 65-79.

Howe, M. L. (2011). The adaptive nature of memory and its illusions. Current Directions in Psychological Science, 20, 312-315.

Howe, M. L., \& Derbish, M. H. (2010). On the susceptibility of adaptive memory to false memory illusions. Cognition, 115, 252-267.

Howe, M. L., Garner, S. R., Dewhurst, S. A., \& Ball, L. J. (2010). Can false memories prime problem solutions? Cognition, 117, 176-181.

Howe, M. L., Garner, S. R., Charlesworth, M., \& Knott, L. M. (2011). A brighter side to memory illusions: False memories prime children's and adults' insight-based problem solving. Journal of Experimental Child Psychology, 108, 383-393.

Howe, M. L., Garner, S. R., \& Patel, M. (2013). The positive consequences of false memories. Behavioural Science and the Law, 31, 652-665. 
Howe, M. L., Garner, S. R., Threadgold, E., \& Ball, L. J. (2015). Priming analogical reasoning with false memories. Memory \& Cognition, 43, 879-895.

Howe, M. L., \& Otgaar, H. (2013). Proximate mechanisms and the development of adaptive Memory. Current Directions in Psychological Science, 22, 6-22.

Howe, M. L., Threadgold, E., Norbury, J., Garner, S., \& Ball, L. J. (2013). Priming children's and adults' analogical problem solutions with true and false memories. Journal of Experimental Child Psychology, 116, 96-103.

Howe, M. L., Wilkinson, S., Garner, S. R., \& Ball, L. J. (2016). On the adaptive function of children's and adults' false memories. Memory, 24, 1062-1077.

Howe, M. L., Wimmer, M. C., Gagnon, N. \& Plumpton, S. (2009). An associative activation theory of children's and adults' memory illusions. Journal of Memory and Language, $60,229-251$.

Israel, L., \& Schacter, D. L. (1997). Pictorial encoding reduces false recognition of semantic associates. Psychonomic Bulletin and Review, 4, 577-581.

Koutstaal, W., Schacter, D. L., \& Brenner, C. (2001). Dual task demands and gist-based false recognition of pictures in younger and older adults. Journal of Memory and Language, 44, $399-426$.

Lövdén, M., \& Johansson, M. (2003). Are covert verbal responses mediating false implicit memory? Psychonomic Bulletin \& Review, 10, 724-729.

Luteijn, F., \& Barelds, D. P. H. (2004). GIT2 Groninger Intelligentie Test 2. Handleiding. Amsterdam: Harcourt Test Publishers.

McBride, D. M., Coane, J. H., \& Raulerson, B. A. (2006). An investigation of false memory in perceptual implicit tasks. Acta Psychologica, 123, 240-260.

McDermott, K. B. (1997). Priming on perceptual implicit memory test can be achieved through 
presentation of associates. Psychonomic Bulletin and Review, 4, 582-586.

McKone, E. (2004). Distinguishing true from false memories via lexical decision as a perceptual implicit test. Australian Journal of Psychology, 56, 42-49.

McKone, E., \& Murphy, B. (2000). Implicit false memory: effects of modality and multiple study presentations on long-lived semantic priming. Journal of Memory and Language, 43, 89109.

Meade, M. L., Hutchison, K. A., \& Rand, K. M. (2010). Effects of delay and number of related list items on implicit activation for DRM critical items in a speeded naming task. Journal of Memory and Language, 62, 302-310.

Meade, M. L., Watson, J. M., Balota, D. A., \& Roediger, H. L. (2007). The roles of spreading activation and retrieval mode in producing false recognition in the DRM paradigm. Journal of Memory and Language, 56, 305-320.

Miller, B., \& Gazzaniga, M.S. (1998). Creating false memories for visual scenes. Neuropsychologia, 36, 513-520.

Nelson, D. L., McEvoy, C. L., \& Schreiber, T. A. (1998). The University of South Florida word association, rhyme, and word fragment norms. http://w3.usf.edu/FreeAssociation/.

Otgaar, H., Sauerland, M., \& Petrila, J. (2013). Novel shifts in memory research and their impact on the legal process. Behavioral Sciences and the Law, 31, 531-540.

Otgaar, H., Howe, M. L., Peters, M., Smeets, T., \& Moritz, S. (2014). The production of spontaneous false memories across childhood. Journal of Experimental Child Psychology, $121,28-41$.

Otgaar, H., Howe, M. L., van Beers, J., van Hoof, R., Bronzwaer, N., \& Smeets, T. (2015). The positive ramifications of false memories using a perceptual closure task. Journal of Applied Research in Memory and Cognition, 4, 43-50. 
Paivio, A. (1991). Dual coding theory: Retrospect and current status. Canadian Journal of Psychology, 45, 255-287.

Perters, M. J. V., Jelicic, M., \& Merckelbach, H. (2015). Inducing false memories: A Dutch version of the Deese/Roediger-McDermott paradigm. Unpublished manuscript.

Pesta, B. J., Murphy, M. D., \& Sanders, R. E. (2001). Are emotionally Charged Lures immune to False Memory? Journal of Experimental Psychology: Learning, Memory and Cognition. 27, 328-338.

Roediger, H., Balota, D., \& Watson, J. (2001). Spreading activation and arousal of false memories. In H. Roediger, J. Nairne, \& A. Surprenant (Eds.), The nature of remembering: Essays in honor of Robert G. Crowder. Science conference series (pp. 95-115). Washington, DC: American Psychological Association.

Roediger, H.L., \& McDermott, K.B. (1995). Creating false memories: remembering words not presented in lists. Journal of Experimental Psychology: Learning, Memory and Cognition, $21,803-14$.

Sadoski, M., \& Paivio, A. (2004). A dual coding theoretical model of reading. In R. B. Ruddell \& N. J. Unrau (Eds.), Theoretical models and processes of reading (5th ed., pp. 1329-1362). Newark, DE: International Reading Association.

Seamon, J. G., Luo, C. R., Schlegel, S. E., Greene, S. E., \& Goldenberg, A. B. (2000). False memory for categorized pictures and words: The category associates procedure for studying memory errors in children and adults. Journal of Memory and Language, 42, 120 -146.

Schacter, D. L. (2012). Adaptive constructive processes and the future of memory. American Psychologist, 67, 603-613.

Schacter, D. L., Chamberlain, J., Gaesser, B., \& Gerlach K. D. (2012) Neuroimaging of true, false, and imaginary memories: Findings and implications. In L. Nadel \& W. Sinnott-Armstrong 
(Eds.), Memory and law (pp. 233-262). New York: Oxford University Press.

Schacter, D. L., Israel, L., \& Racine, C. (1999). Suppressing false recognition in younger and older adults: the distinctiveness heuristic. Journal of Memory and Language, 40, 1-24.

Slotnick, S. D., \& Schacter, D. L. (2004). A sensory signature that distinguishes true from false memories. Nature Neuroscience, 7, 664-672.

Slotnick, S. D., \& Schacter, D. L. (2006). The nature of memory related activity in early visual areas. Neuropsychologia, 44, 2874-2886.

Sommers, M. S., \& Lewis, B. P. (1999). Who really lives next door: Creating false memories with phonological neighbors. Journal of Memory and Language, 40, 83-108.

Stark, C. E. L., Okado, Y., \& Loftus, E.F. (2010). Imaging the reconstruction of true and false memories using sensory reactivation and the misinformation paradigms. Learning and Memory, 17, 485-488.

Tajika, H., Neumann, E., Hamajima, H., \& Iwahara, A. (2005). Eliciting false memories on implicit and explicit memory tests after incidental learning. Japanese Psychological Research, 47, 31-39.

Tse, C. S., \& Neely, J. H. (2005). Assessing activation without source monitoring in the DRM false memory paradigm. Journal of Memory and Language, 53, 532-550.

Tse, C. S., \& Neely, J. H. (2007). Semantic and repetition priming effects for Deese/RoedigerMcDermott (DRM) critical items and associates produced by DRM and unrelated study lists. Memory \& Cognition, 35, 1047-1066.

Underwood, B. J. (1965). False recognition produced by implicit verbal responses. Journal of Experimental Psychology, 70, 122-129.

Van Damme, I., Menten, J., \& d'Ydewalle, G. (2010). The effect of articulatory suppression on implicit and explicit false memory in the DRM paradigm. Memory, 18, 822-830. 
Weinstein, Y., \& Nash, R. A. (2013). False recognition of objects in visual scenes: Findings from a combined direct and indirect memory test. Memory \& Cognition, 41, 60-68.

Weinstein, Y., \& Shanks, D. R. (2010). Rapid induction of false memory for pictures. Memory, $18,533-542$.

Wilkinson, S., Howe, M. L., \& Monaghan, P. (2018). Persistence pays off: False Memories Trump True Memories When Priming Problem Solutions Following a One-week Delay. Manuscript submitted for publication. 
Appendix A: DRM lists

\begin{tabular}{ccccccccc}
\hline Pen & Bread & Chair & Foot & Fruit & Shirt & Cup & Needle & Car \\
\hline Pencil & butter & table & shoe & apple & Blouse & Mug & thread & truck \\
fountain & sandwich & legs & hand & vegetable & sleeves & saucer & pin & Bus \\
leak & Rye & seat & toe & orange & pants & tea & eye & Train \\
quill & Jam & couch & sandals & kiwi & tie & coaster & point & Jeep \\
marker & Milk & desk & soccer & citrus & button & handle & prick & Ford \\
Bic & flour & recliner & heel & pear & jacket & coffee & thimble & Keys \\
scribble & dough & sofa & ankle & banana & collar & straw & haystack & garage \\
crayon & crust & wood & arm & berry & vest & goblet & thumb & tyre \\
\hline
\end{tabular}

Appendix B: Example of degraded representation of the pictures in the perceptual closure task (car)

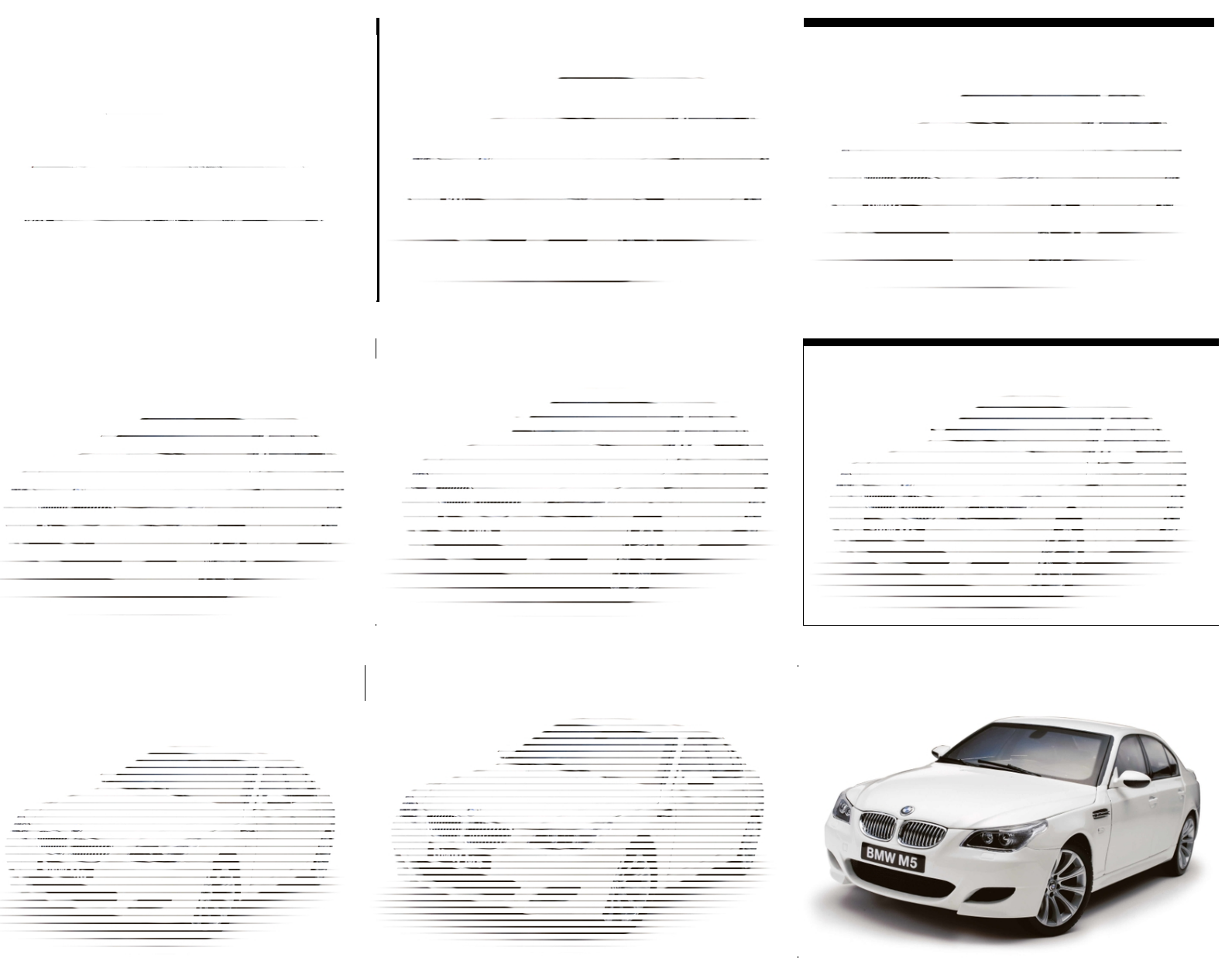


